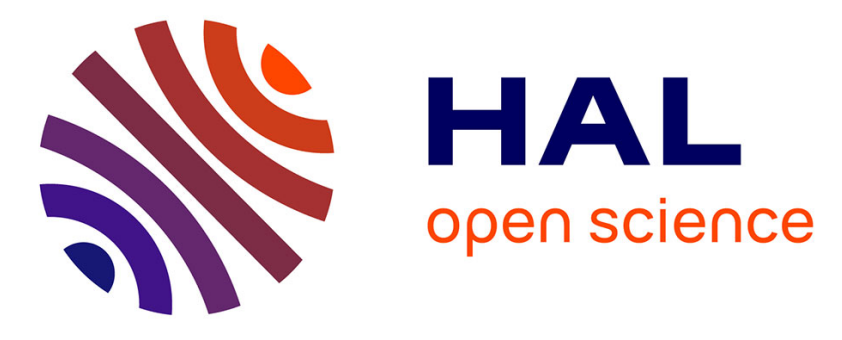

\title{
Numerical life prediction of mechanical fatigue for hot forging tools
}

Katia Mocellin, Matthieu Ferraro, Vincent Velay, Roland E. Logé, Farhad Rezai-Aria

\section{- To cite this version:}

Katia Mocellin, Matthieu Ferraro, Vincent Velay, Roland E. Logé, Farhad Rezai-Aria. Numerical life prediction of mechanical fatigue for hot forging tools. International Journal of Material Forming, 2009, 2 (Supplement 1), pp.Pages 129-132. 10.1007/s12289-009-0537-2 . hal-00509438

\section{HAL Id: hal-00509438}

https://hal-mines-paristech.archives-ouvertes.fr/hal-00509438

Submitted on 12 Aug 2010

HAL is a multi-disciplinary open access archive for the deposit and dissemination of scientific research documents, whether they are published or not. The documents may come from teaching and research institutions in France or abroad, or from public or private research centers.
L'archive ouverte pluridisciplinaire HAL, est destinée au dépôt et à la diffusion de documents scientifiques de niveau recherche, publiés ou non, émanant des établissements d'enseignement et de recherche français ou étrangers, des laboratoires publics ou privés. 


\title{
NUMERICAL LIFE PREDICTION OF MECHANICAL FATIGUE FOR HOT FORGING TOOLS
}

\author{
Katia Mocellin ${ }^{* 1}$, Matthieu Ferraro ${ }^{1}$, Vincent Velay ${ }^{2}$, Roland Logé ${ }^{1}$, Farhad Rézaï-Aria ${ }^{2}$ \\ ${ }^{1}$ Mines ParisTech, CEMEF - Centre de Mise en Forme des Matériaux, CNRS UMR 7635 \\ ${ }^{2}$ Ecole Mines Albi, Toulouse University, CROMeP - Centre Outillages, Matériaux et Procédés,
}

\begin{abstract}
In the forging industry, tools represent an important part in term of production and costs. Enhancing their life cycle is then a challenging issue. Several mechanical and thermal mechanisms are responsible for hot forging tools damage such as wear, thermal and mechanical fatigue. This work will be focused only on the mechanical fatigue life prediction for hot forging tools. Both experimental data analysis and numerical simulation will be discussed in this paper. The aim is to perform qualitative and quantitative indicators of mechanical fatigue. First, experimental data of fatigue tests are used to identify both plastic strain-based Manson Coffin and stress-based Basquin life laws for 2 tool steel grades. These laws are quite classical for fatigue prediction [1-4]. The half-life strain or stress amplitudes are usually used for their identification but these amplitudes are very expensive to obtain from a numerical point of view since it is well known that hot work martensitic steels present a continuous cyclic softening from the first cycle till the rupture. Therefore an important number of cycles have to be simulated to reach these mechanical parameters at half-life. For all theses reasons, an alternative methodology is used [4]. The fatigue life curves are established using the mechanical parameters that are identified from the first hysteresis loops of fatigue experiments. Comparisons are performed with the fatigue laws coming from more classical identification procedure performed at half life cycle. Good agreement is shown between experimental data and the new laws. A lower scattering is even observed in experimental results in comparison to the traditional fatigue laws.
\end{abstract}

Then these new laws are introduced in the commercial software Forge ${ }^{\circledR}$ and are then applied to different industrial cases. A pretty good agreement is observed between predicted tool life and industrial values

KEYWORDS: hot forging, mechanical fatigue, tool lifetime

\section{INTRODUCTION}

The aim of this paper is to determine a fatigue tool life prediction criterion and methodology to be applied in numerical simulations provided with the software Forge $\AA$. The attention is focused here on the mechanical fatigue phenomenon concerning forging tools experiencing the number of strikes less than $10^{3}$. It is thus considered that low cycle fatigue models are prevailing.

In open literature we can find 2 general approaches to predict mechanical fatigue life for hot forging tools:

- First approach is based on an appropriate evaluation of the crack initiation and propagation lives and also the damage criteria for the life prediction [3-4]. The different steps in cracking are considered: initiation and propagation. They have to predict the crack depth from initiation life to the final life. In industrial situation the presence of the crack or damage in the forging tools is acceptable if the tool cracking does not impact yet the final form of the workpiece or the whole integrity of the tool.

- Second approach is based on the analysis of the fatigue life without emphasising the crack initiation or final periods and using the macroscopic values as stress or strain amplitudes. The criterion is related to the material capability to face repetitive and cyclic loading. The actual hot forming tools are subjected to cyclic thermal effects because of the heat transfer from the workpieces to tools and also dissipated energies while metal forming that lead to surface or local temperature enhancements and therefore a decrease of the mechanical properties.

When tools with an engineered-surface are of concern (e.g. nitrided steel) then it is mandatory to take into account in first approach the engineered surface layer thickness that impacts the crack propagation velocity. In this paper the second approach is described and two models are: Basquin (1) law:

\footnotetext{
* Corresponding author: katia.mocellin@mines-paristech.fr, Mines ParisTech, CEMEF - Centre de Mise en Forme des Matériaux, CNRS UMR 7635, BP 207, 1 rue Claude Daunesse, 06904 Sophia Antipolis Cedex, France, tel :00 33 (0)4 93957462 , fax : 0033 (0)4 92389752 .
} 


$$
\frac{\Delta \sigma}{2}=\sigma_{f}^{\prime}\left(N_{R}\right)^{b}
$$

Where, $N_{R}$ is the number of cycles to fracture, $\Delta \sigma$ is the amplitude of stress, $\sigma_{f}^{\prime}$ and $b$, are also two material dependent parameters.

And Manson-Coffin (2) law:

$$
\Delta \varepsilon_{p}=\varepsilon_{f}^{\prime}\left(N_{R}\right)^{c}
$$

Where $\Delta \varepsilon_{p}$ is the amplitude of plastic deformation, $\varepsilon_{f}^{\prime}$ and $c$ are also two material dependent parameters.

The stress and strain amplitudes are obtained from the fatigue hysteresis loops, Figure 1.

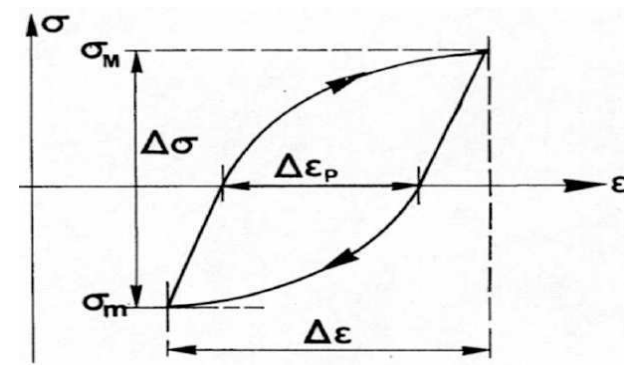

Figure 1: A typical fatigue stress-strain hysteresis loop representation

When the number of strikes in forging tools is limited and generally less than $2.10^{4}$ to $10^{3}$, then one can consider that the low cycle fatigue mode is prevailing.

\section{FATIGUE EXPERIMENTS}

The parameters of the fatigue law are identified by considering several isothermal fatigue tests made in CROMeP laboratory in the framework of different studies. Two tool steels are considered: $\mathrm{X} 38 \mathrm{CrMoV} 5.1$ [3-5] with a hardness of $47 \mathrm{HRC}$ and 55NiCrMoV7 [1] with a hardness of 47 HRC. The experimental database for the first steel consists of about 43 tests performed at various temperatures ranging from $300^{\circ} \mathrm{C}$ to $600^{\circ} \mathrm{C}$. For the second steel 26 tests were used for temperatures ranging from $200^{\circ} \mathrm{C}$ to $550^{\circ} \mathrm{C}$. In the following, the methodology will be explained considering the first steel grade.

The hystersis loops at half-life cycle were used to determine the stress or strain amplitudes. Then both Basquin and Manson-Coffin curves were established and the fatigue life parameters were obtained via least square minimising procedure. Both steel present the continuous cyclic softening that results in change of the rheology of the material during the fatigue test. At half life cycle it is considered the material has reached a stabilized microstructure (in terms of dislocation density and configuration, as well as the precipitation morphologies and sizes, etc) and thus cyclic stress-strain behaviours.

The fatigue life is reported as a function of the stress and strain amplitudes respectively in Figure 2 and 3 at the first, second, fifth or tenth and the half-life cycles. The life curves established for the fist cycles present in general the same trend (slop) as the one for the half-life curve. Due to lower stress and stain amplitude at halflife, the fatigue life curves have the smallest $\sigma_{f}^{\prime}$ and $\mathcal{E}_{f}^{\prime}$.

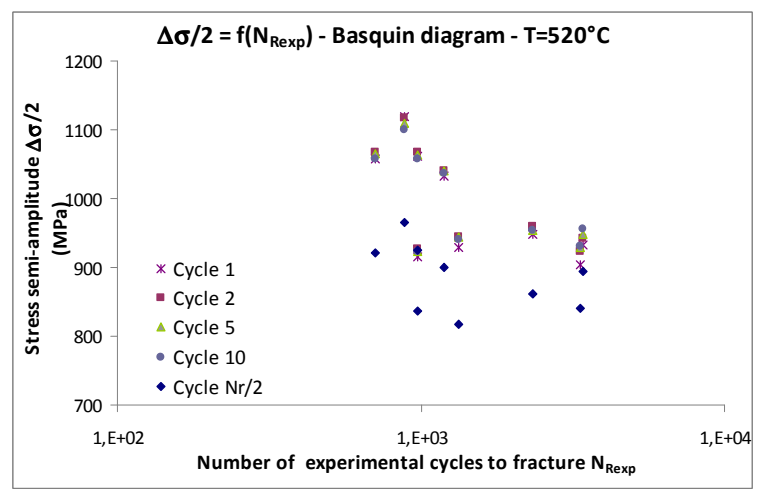

Figure 2: The variation of the fatigue life as a function of the stress amplitude at various fatigue cycles.

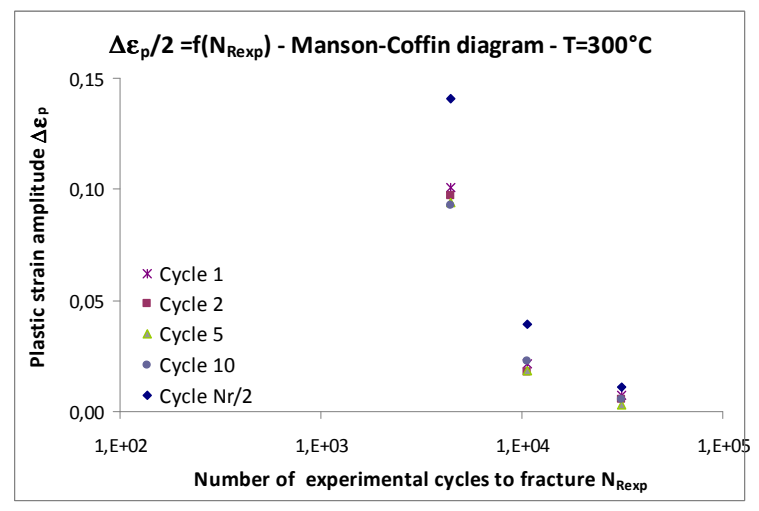

Figure 3: The variation of the fatigue life as a function of the strain amplitude at various fatigue cycles.

Despite of this scattering, the analysis will be performed with the 2 approaches to compare the results in terms of reliability of models to predict the fatigue life.

\section{RESULTS AND DISCUSSIONS}

\subsection{TEMPERATURE DEPENDENCY OF BASQUIN STESS BASED FATIGUE LIFE CURVES}

The stress amplitude vs. fatigue life curves are drastically temperature dependent, Figure 4 . This means that in life prediction of tools the variation of the fatigue life parameters vs temperature should be taken into consideration. To reduce this temperature dependency, a normalized stress amplitude $(\Delta \sigma)$ by the ultimate tensile strength of the material, $\sigma_{u}$, is introduced in equation 3 :

$$
\frac{\Delta S}{2}=\frac{\Delta \sigma}{2 \sigma_{u}}
$$




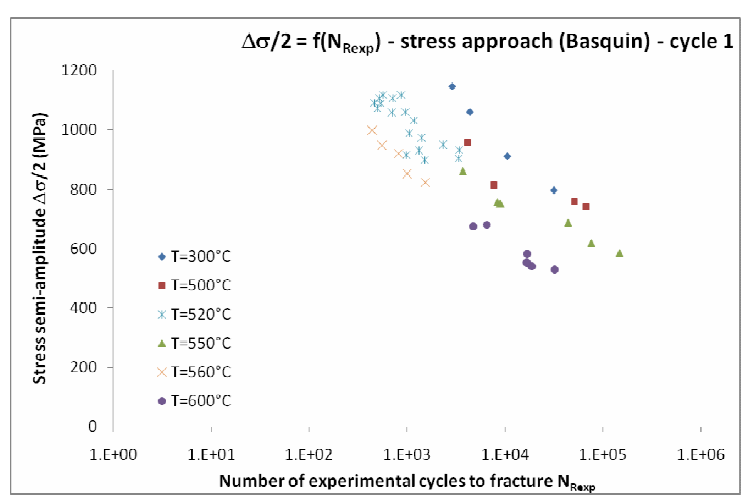

Figure 4: Thermal dependency of the stress amplitude vs. fatigue life curves

This normalized stress parameter reduces temperature dependency of Basquin fatigue life curves, figure 5 . The values of stress amplitude can therefore be related to the fatigue life cycle via an analytical law.

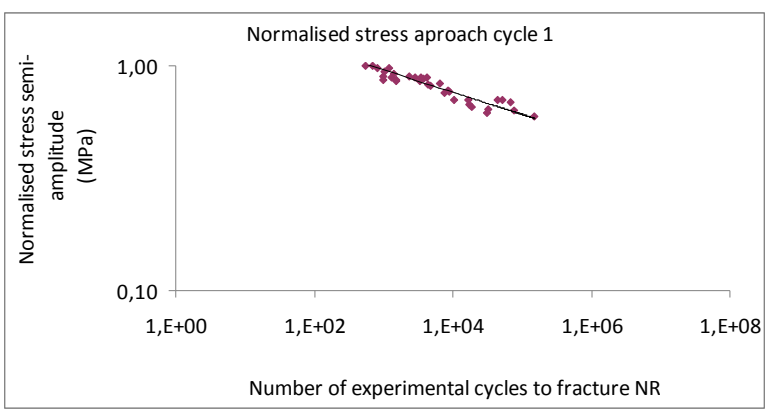

Figure 5: Normalized stress amplitude by the tensile strength vs. the number of fatigue life curves

\subsection{MANSON-COFFIN STRAIN BASED FATIGUE LIFE CURVES}

The Manson-Coffin strain amplitude vs. the fatigue life curves are reported in Figure 6 for all experiments performed at different temperatures. As can be observed one temperature independent fatigue life curve can reasonably rationalized all fatigue life.

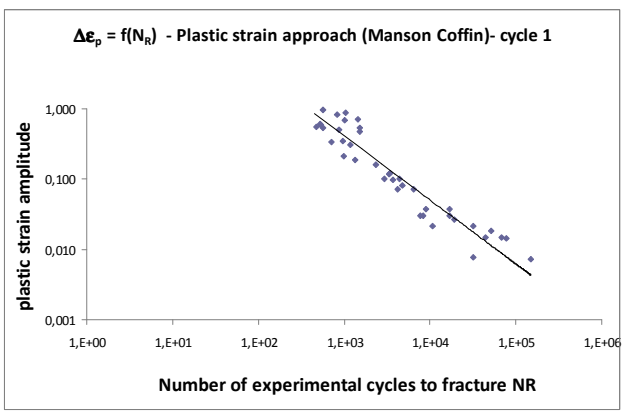

Figure 6: Strain amplitude vs. number of fatigue life cycle curve

The analytical expression obtained in both life prediction approaches are used to predict the fatigue life. The experimental fatigue life and predicted fatigue life are compared in Figure 7 showing an acceptable prediction of the experimental results by a factor 2 .

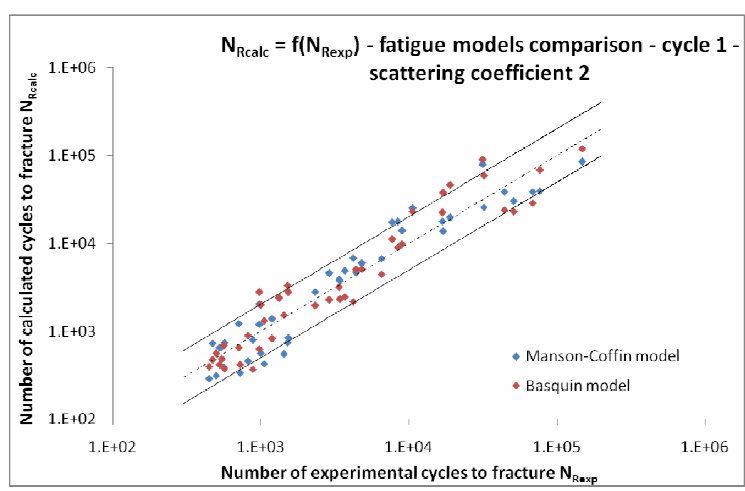

Figure 7: Comparison of predicated and experimental fatigue life using Basquin and Manson-Coffin approaches

\subsection{FATIGUE LIFE BASED OF HALF LIFE APPROACH}

The same fatigue life curves were first established using stabilised hysteresis loops at half-life. Then the constants of life curves were determined. These laws were then used to predict the fatigue life of all experiments. Figure 8 shows the experimental and predicted fatigue life using Manson-Coffin law at half-life and the first cycles.

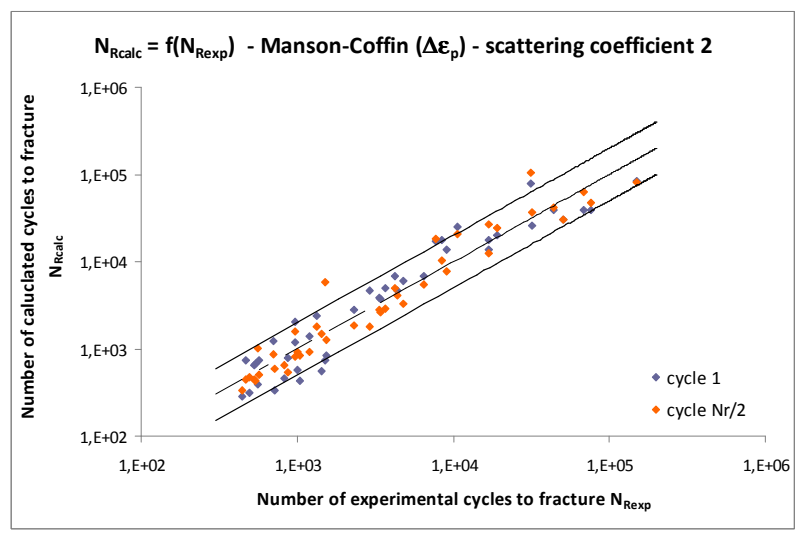

Figure 8: Comparison of the predicted and experimental fatigue life by Manson-Coffin at half- and first cycles.

\section{LIFE PREDICTION SIMULATION USING A RHEOLOGICAL MODEL}

\subsection{LABORATORY FATIGUE EXPERIMENTS}

In this section, we compare the experimental fatigue life with predicted life considering the stress and strain amplitudes extracted directly from the laboratory tests performed at EMAC, and those calculated via the employing an isotropic elastic plastic stress-strain rheology of tensile tests. Figure 9 and 10 show respectively the results obtained for both Basquin and Manson-Coffin approaches. 


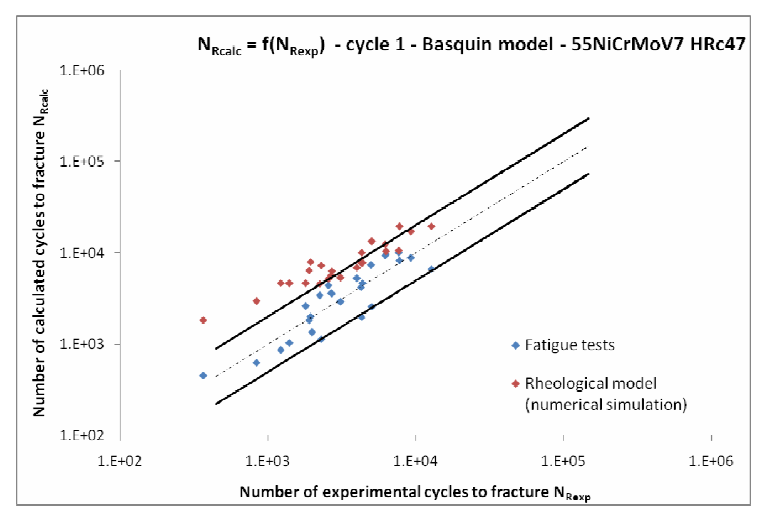

Figure 9: Comparison of experimental and predicted life by Basquin model using experimental and numerical input values

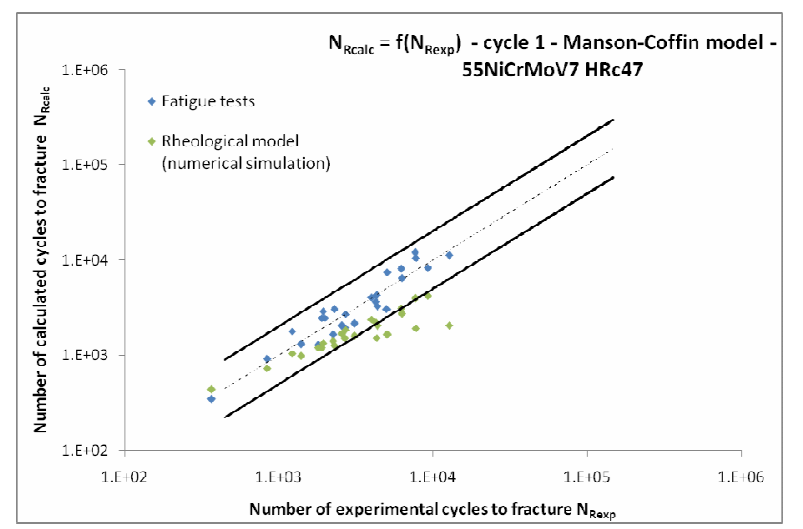

Figure 10: Comparison of experimental and predicted life by Manson-Coffin model using experimental and numerical input values

The high scattering observed for both criterion are mainly due to the behaviour law used in the numerical model. In fact the law is identified on tensile tests where the frequency effect is not taken into account.

\subsection{INDUSTRIAL APPLICATION - SMALL PRODUCTION}

The Basquin and Manson Coffin laws have been implemented in the software Forge in order to predict industrial tools provided by French companies.

The first forging sequences are done on hammer presses for small production cases. Both localisation and quantitative prediction of maximal number of cycles are compared. Table 1 summarizes the values of number of cycles.

Table 1: Industrial and numerical values of maximal number of cycles for a tool used in aeronautical forging

\begin{tabular}{lcc}
\hline & Case 1 & Case 2 \\
\hline Experimental values & 36 to 108 & 150 to 200 \\
\hline Basquin model & 3594 & 2378 \\
\hline Manson Coffin model & 89 & 194 \\
\hline
\end{tabular}

The numerical rheology model can well predict the localisation of crack initiation for both cases. The accuracy is of same order for predicted and observed number of cycles. The acceptable scattering of 2 is fully satisfied.

\subsection{INDUSTRIAL APPLICATIONS - BIG PRODUCTION}

The last industrial case is dealing with high temperature forging production for automotive workpieces.

Table 2: Industrial and numerical values of maximal number of cycles - automotive workpiece

\begin{tabular}{lc}
\hline Experimental values & 10000 \\
\hline Basquin model & 3719 \\
\hline Manson Coffin model & 491 \\
\hline
\end{tabular}

Basquin model gives, in this case, better results, satisfying the scattering value. Additional tests have to be performed to confirm this conclusion.

\section{CONCLUSIONS}

Experimental fatigue tests results have been collected and analysed to provide fatigue life prediction models for two tool steel grades. A new approach consisting of using the stress and strain amplitudes extracted from the first fatigue cycles. Comparisons have been made to evaluate the numerically predicted life for laboratory fatigue tests and industrial forging tools. The acceptable life is predicted for actual tool in small production cases and the automotive forging sequences.

\section{ACKNOWLEDGEMENT}

Authors wish to acknowledge CETIM and a consortium of forging companies involving in the project for financial support and for providing industrial results.

\section{REFERENCES}

[1] Bernhardt G.,Moulinier G.,Brucelle O.,Delagnes D., High temperature low cycle fatigue behaviour of martensitic forging tool steel, Int J Fatigue,21,1999.

[2] Lapovok R., Improvement of die life prediction by minimisation of damage accumulation and optimisation of perform design, J Mater Process Tech, 608-612, 1998

[3] Oudin A.,Lamesle P.,Penazzi L.,Le Roux S., RézaïAria F., Thermomechanical fatigue behaviour and life assessment of hot work tool steels, European Structural Integrity Society, 29:195-201, 2002

[4] Daffos C., Lamesle P ; Rézaï-Aria F, Fatigueoxidation interaction models for life prediction of hot forming tools steels under transient thermomechanical loadings, Int J of Microstructure and Materials Properties, vol. 3, n ${ }^{\circ} 2-3$. - pp.350362, 2008

[5] Oudin A.,Rézaï-Aria F.,Temperature dependence of thermo-mechanical fatigue behaviour of martensitic $5 \%$ chromium steel, Proc Euromat 2000: Advances in mechanical behaviour, plasticity and damage ELSEVIER, 2:1053-1058, 2000. 